\title{
Comparison of 3D Digitally Assisted Visualization System with Current Standard Visualization for the Removal of Vitreous in a Preclinical Model
}

\author{
Marco Mura ${ }^{\mathrm{I}-3}$ \\ Wendy Martin ${ }^{4}$ \\ K Keven Williams ${ }^{4}$ \\ Dina Joy $\mathrm{K}$ Abulon ${ }^{5}$ \\ 'Department of Translational Medicine, \\ University of Ferrara, Ferrara, Italy; \\ ${ }^{2}$ Department of Ophthalmology, \\ University of Illinois, Chicago, IL, USA; \\ ${ }^{3}$ Vitreoretinal Division, King Khaled Eye \\ Specialist Hospital, Riyadh, Saudi Arabia; \\ ${ }^{4}$ Preclinical Development, Alcon Vision \\ LLC, Fort Worth, TX, USA; ${ }^{5} \mathrm{Global}$ \\ Medical Affairs, Alcon Vision LLC, Irvine, \\ CA, USA
}

Correspondence: Marco Mura

Department of Translational Medicine,

University of Ferrara, Via Luigi Borsari 46.

Ferrara, 44I2I, Italy

Tel +390532455845

Fax +39053220735I

Email marco.mura@unife.it
Purpose: Novel 3D digital display systems, such as NGENUITY 3D digitally assisted visualization system (DAVS), can provide enhanced illumination, depth of field, and digital filtering. This study compared vitreous removal using NGENUITY 3D DAVS with a standard surgical microscope.

Methods: This was an in vivo, 2-arm laboratory study in 15 Yorkshire pig eyes. The LuxOR LX3 microscope with NGENUITY 3D DAVS (arm 1) and the LuxOR LX3 microscope alone (arm 2) were used with $5 \times$ optical magnification and Oculus BIOM $200 \mathrm{~mm}$ optics. Standard core and peripheral vitrectomy without scleral depression was performed using the CONSTELLATION Vision System. Residual vitreous weight was assessed in enucleated eyes by a masked observer. Axial length and vitreous weight of contralateral eyes were compared from an additional 14 Yorkshire pigs to confirm that eyes from a single animal were essentially identical.

Results: After vitrectomy, mean \pm SD residual vitreous was significantly smaller with NGENUITY versus standard microscope $(0.143 \pm 0.146$ versus $0.580 \pm 0.269 \mathrm{~g}$, respectively; $P<0.0001)$. Based on a mean initial vitreous weight of $2.5 \mathrm{~g}$, as determined by assessment in contralateral eyes from an additional 14 Yorkshire pigs, the mean percentage vitreous removal was $94 \% \pm 6 \%$ versus $77 \% \pm 11 \%$, respectively. Further, vitreous weight and axial length for contralateral eyes from any single animal in these additional 14 animals were essentially identical, as mean differences were $0.046 \pm 0.035 \mathrm{~g}$ and $0.11 \pm 0.08 \mathrm{~mm}$, respectively.

Conclusion: Vitrectomy with NGENUITY 3D DAVS resulted in significantly less residual vitreous in pig eyes compared with standard microscopy. NGENUITY may improve vitreous removal during vitreoretinal surgery by enhancing visualization.

Keywords: 3D digital display systems, NGENUITY, vitrectomy

\section{Introduction}

Optical microscopy has been routinely used for intraoperative visualization during vitreoretinal surgery. However, its drawbacks include reliance on microscope oculars; excess light exposure; and limitations in field of view, contrast, color, and sharpness. ${ }^{1,2}$ Novel 3D digital display systems can improve illumination and ergonomics, as well as enable surgeons to manipulate the display image to augment visibility.,

The NGENUITY ${ }^{\circledR}$ 3D digitally assisted visualization system (DAVS; Alcon Vision LLC, Fort Worth, TX, USA) displays images from a camera mounted on the microscope in real time using a high-definition digital 3D display. ${ }^{5}$ Digital signals from the camera can be amplified to enhance the brightness of the surgical field, enabling the use of lower endoillumination levels with 3D systems compared with 
standard microscopy, and reducing the risk of phototoxicity. $^{5-8}$ Additionally, the NGENUITY system uses a smaller camera aperture while keeping the eye illumination the same, enhancing the depth of field. Based on theoretical calculations, depth of field with NGENUITY when the camera aperture is reduced to $30 \%$ can be 2 to 3 times greater than that of a standard operating microscope with focal length of $200 \mathrm{~mm}$ and $10 \times$ oculars. $^{2}$

The use of digital image enhancement during vitrectomy can enable surgeons to see through vitreous opacities and potentially improve success and efficiency of vitreoretinal surgery. ${ }^{2}$ Incomplete removal of residual vitreous can result in a number of complications including vitreous incarceration and retinal detachment. ${ }^{9,10}$ NGENUITY color channels can improve vitreous visualization and allow surgeons to improve surgical tasks such as vitreous removal. The purpose of this preclinical study was to assess if the use of NGENUITY 3D DAVS would allow the surgeon to remove more vitreous during vitrectomy surgery compared with a standard surgical microscope.

\section{Methods}

\section{Study Design}

The primary investigation was a prospective, in vivo, 2-arm laboratory study using the CONSTELLATION ${ }^{\circledR}$ Vision System (Alcon Vision LLC) for vitrectomy surgery in porcine eyes. Arm 1 of the study used the LuxOR ${ }^{\circledR}$ LX3 microscope (Alcon Vision LLC) with NGENUITY DAVS visualization system (investigational use); arm 2 used the LuxOR LX3 microscope alone (Table 1). Both microscopes used $5 \times$ optical magnification and were fitted with Oculus BIOM ${ }^{\circledR}$ (OCULUS Optikgeräte GmbH, Wetzlar, Germany) $200 \mathrm{~mm}$ vitrectomy optics. Parameters for both microscopes and vision systems were standardized across groups. This study adhered to the principles found in the ARVO Statement for the Use of Animals in Ophthalmic and Vision Research. Before study initiation, all animal procedures received approval from Alcon's Institutional Animal Care and Use Committee.

\section{Surgical Procedure}

A 3-port valved transconjunctival 23-gauge pars plana vitrectomy was performed in both eyes of live Yorkshire pigs (Sus scrofa, Pratt Livestock, Aubrey, TX, USA) under general anesthesia using CONSTELLATION Vision System in conjunction with the NGENUITY 3D
Table I Equipment Settings

\begin{tabular}{|l|c|c|}
\hline & $\begin{array}{c}\text { Arm I } \\
\text { NGENUITY 3D DAVS }\end{array}$ & $\begin{array}{c}\text { Arm 2 } \\
\text { Standard } \\
\text { Microscope }\end{array}$ \\
\hline $\begin{array}{l}\text { Vitrectomy } \\
\text { platform }\end{array}$ & $\begin{array}{c}\text { CONSTELLATION } \\
\text { Vision System }\end{array}$ & $\begin{array}{c}\text { CONSTELLATION } \\
\text { Vision System }\end{array}$ \\
\hline $\begin{array}{l}\text { Visualization } \\
\text { system }\end{array}$ & $\begin{array}{c}\text { LuxOR LX3 with } \\
\text { NGENUITY 3D DAVS }\end{array}$ & $\begin{array}{c}\text { LuxOR LX3 with } \\
\text { standard binocular }\end{array}$ \\
\hline $\begin{array}{l}\text { Vitrectomy } \\
\text { optics }\end{array}$ & Oculus BIOM 200 mm & $\begin{array}{c}\text { Oculus BIOM 200 mm } \\
\text { Optimal } \\
\text { magnification }\end{array}$ \\
\hline
\end{tabular}

Abbreviation: DAVS, digitally assisted visualization system.

visualization system paired with the LuxOR LX3 microscope or LuxOR LX3 alone (Table 1). NGENUITY 3D DAVS parameters for vitrectomy are summarized in Table 2. Posterior vitreous detachment was followed by a standard core and peripheral vitrectomy without scleral depression. To reduce surgical bias, the visualization method was alternated between the left eye (OS) and right eye (OD).

\section{Residual Vitreous Assessment}

For residual vitreous assessment, enucleated eyes were trimmed of adnexa (Figure 1A), and each eye was bisected posterior to the lens by a masked prosector (Figure 1B). Any residual irrigating solution was drained, and the eye was blotted dry to remove any extraneous solution. Both segments of the bisected eye were weighed by a masked observer. After residual vitreous was stripped from the remaining ocular tissues with a surgical sponge (Figure 1C and D), the eye segments were weighed

Table 2 NGENUITY 3D DAVS Settings Applied During Surgery

\begin{tabular}{|l|c|}
\hline Parameters & NGENUITY 3D DAVS Settings \\
\hline Camera & Standard \\
Light profile & Xenon \\
Gain & I \\
Channel & Off \\
RGB & $100,100,100$ \\
Brightness & 49.00 \\
Contrast & 52.50 \\
Gamma & 1.00 \\
Hue & 32 \\
Saturation & 87 \\
\hline
\end{tabular}

Abbreviations: DAVS, digitally assisted visualization system; RGB, red green blue. 

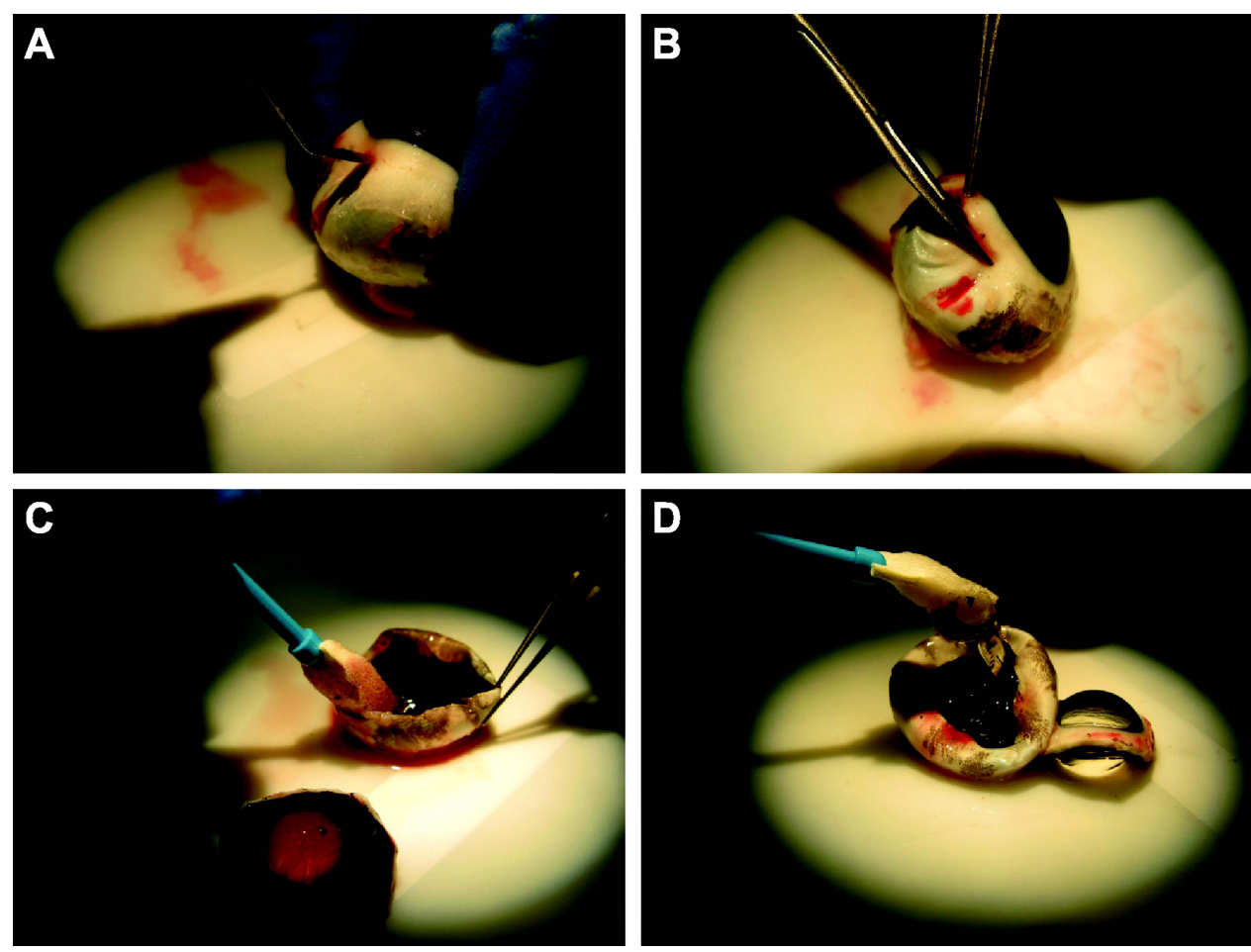

Figure I Residual vitreous assessment. Posterior segment of the eye was removed (A), the eye was bisected (B), and residual vitreous was stripped (C and D).

a second time. The second weight was subtracted from the first to determine the residual vitreous weight. Paired differences in residual vitreous between arms were analyzed using a paired $t$-test at the 0.05 type I level.

\section{Assessment of Axial Length and Vitreous Volume in Contralateral Eyes}

To model clinical settings, the vitrectomy portion of this study was conducted in live pigs; all vitrectomies were undertaken by the same surgeon. Comparison of postsurgical residual vitreous weight was based on an assumption that both eyes from a single animal were essentially identical in size and vitreous weight before surgery. To confirm this assumption, a separate study was conducted to compare axial length and vitreous weight of the right and left eyes of the porcine model. These data also provided the basis by which percentage vitreous removal was determined in the main experiment.

Axial length was assessed on 14 Yorkshire pigs (Sus scrofa, Pratt Livestock, Aubrey, TX, USA) under general anesthesia using A-scan with Lenstar LS 900 (Haag-Streit AG, Koeniz, Switzerland) optical low-coherence reflectometry biometer. The pigs were then euthanized and vitreous weight assessments were performed as described above.
Differences in vitreous weights between eyes were determined for individual animals and for the group mean, with the confidence interval (CI) determined for the mean absolute difference, based on $t$-distribution. $P$ values were calculated using paired $t$-test.

\section{Results}

\section{Vitreous Removal with NGENUITY 3D DAVS versus Standard Surgical Microscope}

To assess vitreous removal, eyes from 15 Yorkshire pigs weighing 32 to $34 \mathrm{~kg}$ (4 females and 11 males, 2-3 months old) were used. Mean $\pm \mathrm{SD}$ residual vitreous was $0.143 \pm 0.146 \mathrm{~g}$ after vitrectomy using the NGENUITY 3D DAVS compared with $0.580 \pm 0.269$ g using the LuxOR microscope alone. Vitrectomy using NGENUITY 3D DAVS resulted in significantly greater vitreous removal compared with standard visualization microscopy $(P<0.0001$; Figure $2 \mathrm{~A})$; the mean paired difference was $0.436 \mathrm{~g}$. Based on the mean initial vitreous weight of $2.5 \mathrm{~g}$ (as described in the following section), the mean percentage of vitreous removed was $94 \% \pm 6 \%$ with NGENUITY 3D DAVS visualization compared with $77 \% \pm 11 \%$ with standard visualization (Figure 2B). 
A

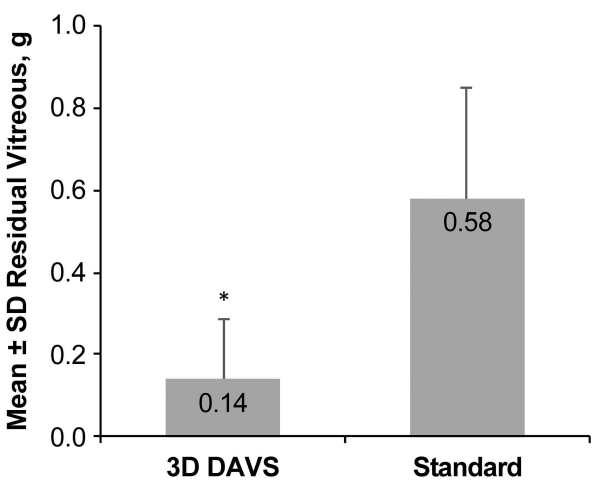

B

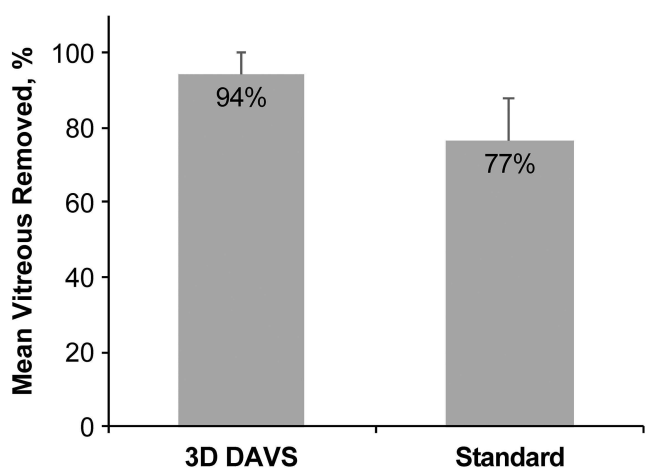

Figure 2 Comparison of NGENUITY 3D DAVS and a standard visualization system for the removal of vitreous. Mean residual vitreous (A) and mean percentage of vitreous removed $(\mathbf{B})$ are shown $(\mathrm{n}=15)$. $* P<0.0001$.

Abbreviation: 3D DAVS, 3D digitally assisted visualization system.

\section{Contralateral Comparability of Ocular Parameters in the Porcine Eye Model}

To compare vitreous weight and axial length in contralateral eyes, eyes from 14 Yorkshire pigs weighing 27 to $36 \mathrm{~kg}$ (5 females and 9 males, 2-3 months old) were used. Mean \pm SD vitreous weight was $2.47 \pm 0.15$ and $2.49 \pm 0.15 \mathrm{~g}$ for OD and OS, respectively (Table 3). Differences in vitreous weight between OD and OS ranged from 0.001 to $0.118 \mathrm{~g}$ (Table 4), with a mean difference of $0.046 \pm 0.035 \mathrm{~g}$. Mean percentage difference in vitreous weight for the contralateral eyes was 1.87. Mean $\pm \mathrm{SD}$ axial length was $17.5 \pm 0.2 \mathrm{~mm}$ for both $\mathrm{OD}$ and OS. Difference in axial length between OD and OS ranged from 0 to $0.28 \mathrm{~mm}$, with an average mean difference of $0.11 \pm 0.08 \mathrm{~mm}$. There was no correlation between body weight and axial length $\left(\mathrm{R}^{2}=0.048\right)$ or between vitreous weight and axial length $\left(\mathrm{R}^{2}=0.153\right)$.

\section{Discussion}

In this study, we compared the use of NGENUITY 3D DAVS and a standard microscope for pars plana vitrectomy in porcine eyes, with $5 \times$ optical magnification in both systems. Vitrectomy with 3D DAVS resulted in significantly less residual vitreous in the eye compared with vitrectomy using only a standard microscope $(P<0.0001)$. Additionally, our analysis of ocular parameters of the porcine eyes found that there were minimal variations in vitreous weight or axial length between a given animal's OD and OS. Based on our measurements, mean vitreous weight was approximately $2.5 \mathrm{~g}$ for both OS and OD. These data were used to calculate the percentage of vitreous removed with 3D DAVS system (94\%) compared with the standard microscope $(77 \%)$. The greater percentage of vitreous removal achieved with NGENUITY 3D DAVS may be a consequence of better visualization during vitrectomy (Figure 3).

$3 \mathrm{D}$ heads-up visualization systems provide a number of surgery-enhancing tools that may result in better outcomes, including better depth of field and the use of digital color filters. Enhanced depth of field can bring multiple planes in focus and allows for a broader field of view. ${ }^{7}$ Studies that assessed surgical experience reported enhanced depth of field with NGENUITY. ${ }^{4,5}$ Specifically, a 3D system received significantly higher ratings for depth perception from both surgeons and observers compared with a standard microscope $(P<0.001) .{ }^{11}$ Another study reported that with an aperture of $25 \%$, the depth of field

Table 3 Comparison of OD and OS

\begin{tabular}{|c|c|c|c|c|}
\hline & \multirow{2}{*}{$\begin{array}{c}\text { Mean } \pm \text { SD Vitreous } \\
\text { Weight, } g\end{array}$} & \multirow{2}{*}{$\begin{array}{c}\text { Mean } \pm \text { SD Axial } \\
\text { Length, } \mathbf{m m}\end{array}$} & \multicolumn{2}{|c|}{ Difference Between OD and OS } \\
\hline & & & $\begin{array}{c}\text { Mean } \pm \text { SD Difference in Vitreous } \\
\text { Weight, } g\end{array}$ & $\begin{array}{c}\text { Percentage Difference in Vitreous } \\
\text { Weight, } \%\end{array}$ \\
\hline OD & $2.47 \pm 0.15$ & $17.48 \pm 0.19$ & $0.046 \pm 0.035$ & 1.87 \\
\hline OS & $2.49 \pm 0.15$ & $17.54 \pm 0.20$ & & \\
\hline
\end{tabular}

Abbreviations: OD, right eye; OS, left eye. 
Table 4 Vitreous Weight and Axial Length for Contralateral Eyes in Comparison Analysis

\begin{tabular}{|c|c|c|c|c|c|c|}
\hline \multirow[t]{2}{*}{ Animal } & \multicolumn{3}{|c|}{ Vitreous Weight, g } & \multicolumn{3}{|c|}{ Axial Length, mm } \\
\hline & OD & os & $\begin{array}{c}\text { Difference Between OD } \\
\text { and OS, } \mathrm{g}\end{array}$ & OD & os & $\begin{array}{l}\text { Difference Between OD } \\
\text { and OS, } \mathrm{mm}\end{array}$ \\
\hline 1 & 2.1517 & 2.2378 & 0.0861 & 17.46 & 17.18 & 0.28 \\
\hline 2 & 2.4288 & 2.3884 & 0.0404 & 17.19 & 17.28 & 0.09 \\
\hline 3 & 2.5095 & 2.5925 & 0.0830 & 17.82 & 17.71 & 0.11 \\
\hline 4 & 2.7157 & 2.7145 & 0.0012 & 17.69 & 17.72 & 0.03 \\
\hline 5 & 2.5450 & 2.5368 & 0.0082 & 17.42 & 17.53 & 0.11 \\
\hline 6 & 2.3515 & 2.3408 & 0.0107 & 17.60 & 17.80 & 0.20 \\
\hline 7 & 2.4919 & 2.5024 & 0.0105 & 17.55 & 17.60 & 0.05 \\
\hline 8 & 2.3787 & 2.4473 & 0.0686 & 17.61 & 17.77 & 0.16 \\
\hline 9 & 2.4122 & 2.5300 & 0.1178 & 17.52 & 17.55 & 0.03 \\
\hline 10 & 2.4118 & 2.3767 & 0.0351 & 17.27 & 17.36 & 0.09 \\
\hline II & 2.3791 & 2.3124 & 0.0667 & 17.21 & 17.34 & 0.13 \\
\hline 12 & 2.6853 & 2.7471 & 0.0618 & 17.66 & 17.66 & 0 \\
\hline 13 & 2.5239 & $2.487 \mid$ & 0.0368 & 17.45 & 17.68 & 0.23 \\
\hline 14 & 2.6228 & 2.6008 & 0.0220 & 17.32 & 17.34 & 0.02 \\
\hline Mean (SD) & $2.47(0.15)$ & $2.49(0.15)$ & $0.0464(0.0352)$ & $17.48(0.18)$ & $17.54(0.20)$ & $0.11(0.08)$ \\
\hline$P$ value (OD vs $O S)$ & & & 0.35 & & & 0.15 \\
\hline
\end{tabular}

Note: $P$ values were calculated using paired $t$-test.

Abbreviations: OD, right eye; OS, left eye.

was considerably greater with a $3 \mathrm{D}$ system compared with a standard microscope (32 vs $14 \mathrm{~mm}$, respectively), although there was a marked loss of brightness. ${ }^{12}$ Additionally, peripheral acuity was reported to be better when using the NGENUITY system, which provides high

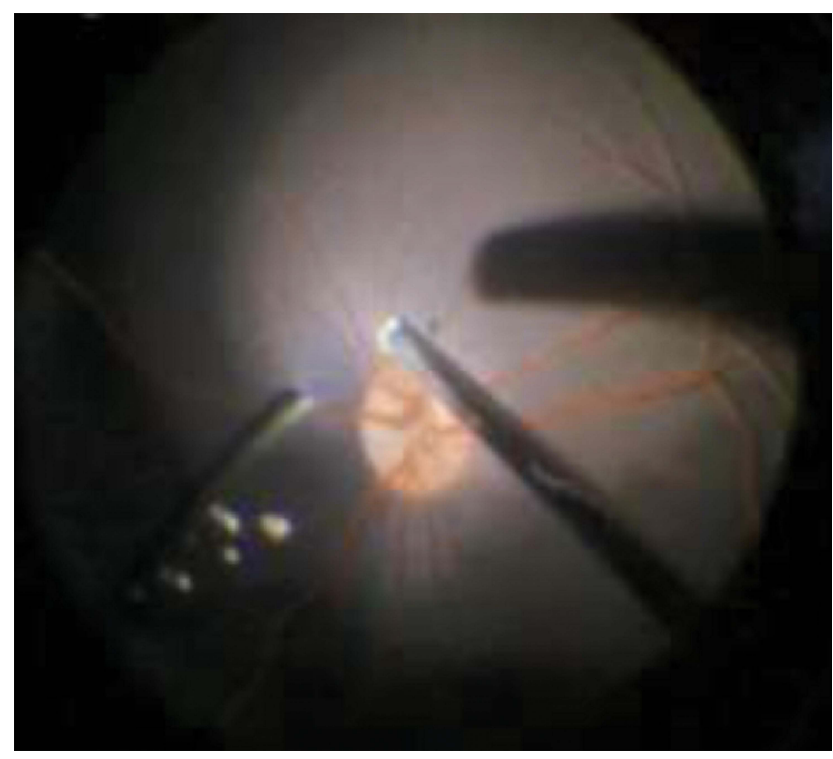

Figure 3 Vitreous visualization using NGENUITY 3D digitally assisted visualization system alternated between right eye and left eye to reduce surgical bias; vitreous was highlighted in a blue color. magnification with a wide field of view, ${ }^{13}$ which may have contributed to the more complete vitreous removal using the NGENUITY system.

With 3D visualization systems, digital color filters can be used to enhance visibility of specific tissues; for example, blue tint can be used to better identify the vitreous. In porcine eyes, color channels affected the image quality, and the use of blue channel enhanced visualization of the peripheral vitreous. ${ }^{13}$ The use of digital filters and highresolution magnification in the $3 \mathrm{D}$ group may provide optimal visualization of the vitreous remnants without the need for triamcinolone staining. ${ }^{7}$ Enhanced visualization of peripheral vitreous achieved as a result of better peripheral acuity and the use of digital filters may lead to more complete vitreous removal and better surgical outcomes, consistent with findings reported for NGENUITY 3D DAVS in this study.

Head-up surgery using 3D systems has been demonstrated to work well for routine vitreoretinal procedures, providing a large viewing display and higher magnification levels as well as enabling electronic amplification of the camera's signal to augment the brightness of the surgical field without exposing the retina to additional light, contributing to improved ocular surgery outcomes. $^{12,14} \mathrm{~A}$ number of studies demonstrated that 
vitreoretinal surgeries using 3D systems could be performed at $10 \%$ endoillumination without a decrease of image quality; conventional surgery was reported as typically using $35 \%$ endoillumination. . $^{8,11,13,15}$ A study that compared efficacy and safety of a 3D system with standard of care also found that minimum endoillumination was significantly lower with the $3 \mathrm{D}$ system compared with a standard microscope $(P=0.008) .{ }^{16}$ These results suggest that digital enhancements of NGENUITY system parameters (ie, brightness, color balance, and contrast) allow the use of low endoillumination levels and may reduce the risk of phototoxicity during surgery.

A strength of this study was that the surgeon was experienced with the NGENUITY 3D DAVS, as use of this system may require an initial learning curve for the surgeon. ${ }^{4}$ A limitation of this study was that masking of the experimental groups throughout the study was not possible. However, measurements (eg, vitreous weight) were taken by a single masked prosector. Additionally, we may not have removed all vitreous from the porcine eyes in our baseline comparator model, resulting in an overestimation of the percentage removal of vitreous in both arms of our experiment; nonetheless, the NGENUITY 3D DAVS removed a significantly greater percentage of vitreous than using the LuxOR microscope alone.

\section{Conclusions}

The current study quantitatively evaluated removal of vitreous in porcine eyes using the NGENUITY 3D DAVS versus a standard microscope. Based on our measurements, $17 \%$ more vitreous was removed from eyes using the NGENUITY 3D DAVS compared with eyes using a standard microscope. The amount of residual vitreous in eyes was significantly less in the 3D DAVS group versus the standard group, potentially because the surgeon could better visualize vitreous in the periphery, leading to more complete vitreous removal. In porcine eyes, color channels affected the image quality: specifically, the use of blue channel enhanced visualization of the peripheral vitreous. These findings suggest that NGENUITY 3D DAVS can be used successfully for vitrectomy; the combination of digital filters and high-resolution magnification may provide optimal visualization of the vitreous remnants without the need for triamcinolone staining. Future studies are needed to evaluate clinical benefits of enhanced visualization of vitreous using NGENUITY 3D DAVS.

\section{Abbreviations}

DAVS, digitally assisted visualization system; OD, right eye; OS, left eye.

\section{Data Sharing Statement}

The data generated for this study were preclinical in nature. The data are located at Alcon Vision, Ft. Worth, TX and are not publicly available.

\section{Acknowledgments}

Medical writing assistance was provided by Natalia Zhukovskaya, PhD, of ICON (North Wales, PA), and was funded by Alcon. Data in this manuscript were presented, in part, at the 19th European Society of Retina Specialists (EURETINA) Congress in Paris, France, September 2019 and at the American Academy of Ophthalmology Annual Meeting in San Francisco, United States, September 2019.

\section{Funding}

This study was funded by Alcon Vision LLC. Alcon assisted with the design and conduct of the study; collection, management, analysis, and interpretation of the data; and preparation, review, and approval of the manuscript.

\section{Disclosure}

M. Mura was a consultant for Alcon Vision LLC and Bayer Healthcare Pharmaceuticals; W. Martin and K.K. Williams are employees at Alcon Vision LLC; D.J.K. Abulon was an employee of Alcon Vision LLC at the time of the study. The authors report no other conflicts of interest in this work.

\section{References}

1. Adam MK, Ho AC. The pros and cons of heads-up surgery. Review of Ophthalmology. Available from: https://www.reviewofophthalmology. com/article/the-pros-and-cons-of-headsup-surgery. Accessed June 17, 2021.

2. Franklin AJ, Sarangapani R, Yin L, Tripathi B, Riemann C. Digital vs analog surgical visualization for vitreoretinal surgery: the future is here now for the surgical viewing experience. Retinal Physician. 2017;14 (34-36):38-40.

3. Charles S. Getting specific about 3-D visualization: an understanding of the features and benefits of this new technology is necessary to its successful implementation. Available from: http://retinatoday.com/ 2017/12/getting-specific-about-3-d-visualization/. Accessed June 17, 2021.

4. Agranat JS, Miller JB, Douglas VP, et al. The scope of three-dimensional digital visualization systems in vitreoretinal surgery. Clin Ophthalmol. 2019;13:2093-2096. doi:10.2147/OPTH. S213834 
5. Rizzo S, Abbruzzese G, Savastano A, et al. 3D surgical viewing system in ophthalmology: perceptions of the surgical team. Retina. 2018;38(4):857-861. doi:10.1097/IAE.0000000000002018

6. Kita M, Mori Y, Hama S. Hybrid wide-angle viewing-endoscopic vitrectomy using a 3D visualization system. Clin Ophthalmol. 2018;12:313-317. doi:10.2147/OPTH.S156497

7. Coppola M, La Spina C, Rabiolo A, Querques G, Bandello F. Headsup 3D vision system for retinal detachment surgery. Int $J$ Retina Vitreous. 2017;3:46. doi:10.1186/s40942-017-0099-2

8. Adam MK, Thornton S, Regillo CD, Park C, Ho AC, Hsu J. Minimal endoillumination levels and display luminous emittance during three-dimensional heads-up vitreoretinal surgery. Retina. 2017;37 (9):1746-1749. doi:10.1097/IAE.0000000000001420

9. van Overdam KA, van Etten PG, van Meurs JC, Manning SS. Vitreous wiping, a new technique for removal of vitreous cortex remnants during vitrectomy. Acta Ophthalmol. 2019;97(5):e747-e752. doi:10.1111/ AOS.13991

10. Wang A, Zhao Z, Xu Q, Wang Y, Liao H. Risk factors for residual vitreous cortex at the fovea after posterior vitreous detachment during vitrectomy in ocular trauma. $J$ Ophthalmol. 2019;2019:1-6. doi:10.1155/2019/4312958

11. Romano MR, Cennamo G, Comune C, et al. Evaluation of 3D heads-up vitrectomy: outcomes of psychometric skills testing and surgeon satisfaction. Eye. 2018;32(6):1093-1098. doi:10.1038/ s41433-018-0027-1
12. Eckardt C, Paulo EB. Heads-up surgery for vitreoretinal procedures: an experimental and clinical study. Retina. 2016;36(1):137-147. doi:10.1097/IAE.0000000000000689

13. Palacios RM, de Carvalho ACM, Maia M, Caiado RR, Camilo DAG, Farah ME. An experimental and clinical study on the initial experiences of Brazilian vitreoretinal surgeons with heads-up surgery. Graefes Arch Clin Exp Ophthalmol. 2019;257(3):473-483. doi:10.1007/s00417-01904246-w

14. Velasque L, Arbousoff N, Rigaudier F, et al. Lux study: contribution of a three-dimensional, high dynamic range, ultra-high-definition heads-up visualization system to a significant delivered light intensity decrease during different types of ocular surgeries. J Fr Ophtalmol. 2021;44(8):1129-1141. doi:10.1016/j.jfo.2021.01.006

15. Zhang Z, Wang L, Wei Y, Fang D, Fan S, Zhang S. The preliminary experiences with three-dimensional heads-up display viewing system for vitreoretinal surgery under various status. Curr Eye Res. 2019;44 (1):102-109. doi:10.1080/02713683.2018.1526305

16. Talcott KE, Adam MK, Sioufi K, et al. Comparison of a three-dimensional heads-up display surgical platform with a standard operating microscope for macular surgery. Ophthalmol Retina. 2019;3(3):244-251. doi:10.1016/j.oret.2018.10.016
Clinical Ophthalmology

\section{Publish your work in this journal}

Clinical Ophthalmology is an international, peer-reviewed journal covering all subspecialties within ophthalmology. Key topics include: Optometry; Visual science; Pharmacology and drug therapy in eye diseases; Basic Sciences; Primary and Secondary eye care; Patient Safety and Quality of Care Improvements. This journal is indexed on PubMed

Submit your manuscript here: https://www.dovepress.com/clinical-ophthalmology-journal

\section{Dovepress}

Central and CAS, and is the official journal of The Society of Clinical Ophthalmology (SCO). The manuscript management system is completely online and includes a very quick and fair peer-review system, which is all easy to use. Visit http://www.dovepress.com/ testimonials.php to read real quotes from published authors. 